May - 2017

\title{
Book Review: Designing Teaching and Learning for a Digital Age
}

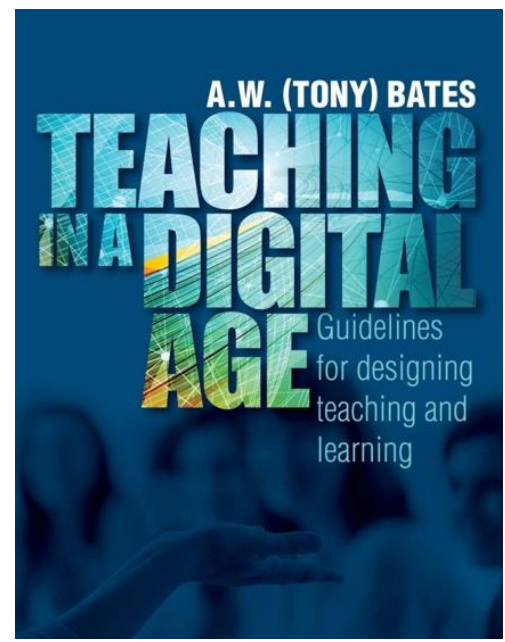

Bates, T. (2015). Teaching in a digital age: Guidelines for designing teaching and learning for a digital age. Canada: Tony Bates Associates Ltd. ISBN: 978-0-99526920-0. (pp.518). Retrieved from https://opentextbc.ca/teachinginadigitalage/

Reviewed by: Serpil Kocdar, PhD, Anadolu University, Turkey

Tony Bates, one of the most well-known educational technologists with more than 50 years of experience in the field of education, delivers his wisdom to readers in Teaching in a Digital Age. The target audience of the author is teachers and instructors who have concerns about how to use technology effectively for teaching. The book provides the principles and methods for effective teaching and learning in a digital age. Bates aims to guide teachers and instructors to take the helm in helping their students to develop adequate levels of knowledge and digital skills to be successful in the digital age. The author uses the terms "teacher" and "instructor" interchangeably to distinguish between K-12 classrooms and postsecondary education; however, he suggests using the term teacher instead of instructor as the latter implies "a transmission model of education," while the former refers to "the facilitation of learning" (p. 2).

The book consists of 12 chapters in six thematic sections. These sections and chapters are:

- Chapter 1: Fundamental change in education

- Chapters 2-5: Epistemology and teaching methods

- Chapters 6-8: Media and technology

- Chapters 9-10: Modes of delivery and open education

- Chapter 11 and Appendix 1: Ensuring quality in teaching in a digital age

- Chapter 12: Institutional support

Chapter 1, Fundamental Change in Education, presents the rationale of the book, constituting a basis for other chapters. In this chapter, changes in society, markets and students are explained as well as the 
reasons why teachers and instructors should revise their methods of teaching according to these changes. The chapter also reviews how technology changes the methods of teaching due to the changing needs of students in a digital age.

Chapter 2, The Nature of Knowledge and the Implications for Teaching, divulges the nature of knowledge and its influence on learning theories and teaching methods. The chapter also includes the four most common theories of learning which are behaviorism, cognitivism, constructivism, and connectivism, along with their epistemology.

Chapter 3, Methods of Teaching: Campus-Focused, discusses teaching methods commonly used on campus-based learning environments. Five perspectives on teaching are examined-the transmission, apprenticeship, developmental, nurturing, and social reform. These abovementioned perspectives are related to epistemologies and theories of learning, with an emphasis on their relevance to a digital age. The chapter guides readers to a discussion of the general strengths and weaknesses of each approach, identify the extent to which each approach meets the needs of learners in a digital age and choose an appropriate teaching method (or mix of methods) for their teaching context.

Chapter 4, Methods of Teaching with an Online Focus, covers key approaches to the design of online teaching and learning. The chapter involves design models such as classroom-type online learning, the ADDIE model, online collaborative learning, competency-based learning, communities of practice, and agile design. It provides an opportunity for teachers and instructors to look into the strengths and weaknesses of each model and decide on the most suitable model or combination of models for their teaching.

Chapter 5, MOOCs, primarily focuses on many aspects of MOOCs including a brief history and definition, the differences between various kinds, MOOCs and other forms of online and open learning, strengths and weaknesses, and disruptive impacts of political, social, and economic drivers of the courses. The chapter also allows the readers to make decisions on developing or investing and the types to advance MOOCs.

Chapter 6, Understanding Technology in Education, provides information on how to choose and use technologies and media for teaching and learning. The author identifies three core dimensions of media and technology namely:

1. Broadcast (one-way) or communicative (two way) media;

2. Synchronous or asynchronous technologies, including live recorded media; and

3. Single or rich media.

The chapter also covers a short history of educational technology, the difference between media and technology, and the foundations of educational media.

Chapter 7, Pedagogical Differences between Media, focuses on the distinctive pedagogical characteristics of various media consisting of text, audio, video, computing, and social media. It aims to provide a framework for analyzing the pedagogical characteristics of educational media and to enable readers to apply that analysis to any particular module of teaching. 
Chapter 8, Choosing and Using Media in Education: The SECTIONS Model, provides a framework for making appropriate decisions about the use of media and technology for teaching and learning. The framework includes the SECTIONS model which consists of 8 dimensions: Students, Ease of use, Costs, Teaching functions, Interaction, Organizational issues, Networking, and lastly, Security and privacy.

Chapter 9, Modes of Delivery, explores three modes of delivery which are campus-based; blended or fully online and helps to determine the most appropriate mode of delivery for their courses or programs implying the factors influencing their decision.

Chapter 10, Trends in Open Education, discusses the disruptive implications of open educational resources, open textbooks, open research, and open data in higher education. The author claims that the open movement is more revolutionary than MOOCs, so it will lead to more radical changes in education. The chapter also guides readers to decide when to use open educational resources and when to create their own materials as well as to maximize the use of digital materials.

Chapter 11, Ensuring Quality Teaching in a Digital Age, guides readers about how to develop quality courses. It suggests nine steps for designing and delivering quality teaching in a digital age specifically: (1) Deciding how you want to teach, (2) deciding what kind of course or program, (3) working in a team, (4) building on existing resources, (5) mastering the technology, (6) setting appropriate learning goals, (7) designing course structure and learning activities, (8) communicating, and (9) evaluating and innovating.

Chapter 12, Supporting Teachers and Instructors in a Digital Age, emphasizes the need for professional development and training of teachers to ensure high quality teaching in a digital age. It also covers learning technology support systems, team teaching for large classes, and the need for an institutional strategy for teaching in a digital age.

Appendix 1, Building an Effective Learning Environment, complements Chapter 11, consisting of key components of a high-quality learning environment. The chapter covers integrating design principles within a rich learning environment, definition of a learning environment, learner characteristics, content management, skill development, learner support, resource use, learning assessment, and basics for a good design.

The book is very well organized and structured. Its content as well as its open access and interactive design makes this masterpiece unique. It provides a critical analysis of the key issues for not only teachers and instructors but also for researchers, practitioners, decision-makers in the field, and students who intend to have a career in educational technology or open and distance learning. It also provides options and practical guidelines to assist readers in making decisions about their teaching. Presentation of the historical background of the events or concepts enables readers to grasp the foundations of the concepts and therefore have deeper insights on the subject. The book covers all the main contemporary issues in the field including updated information; updates and revisions are provided as well. However, the book gives the impression that it was written for readers in developed countries; so aforementioned perspectives or cases regarding teaching in developing countries in a digital age, especially given the author's experiences, could also be mentioned in the chapters, scenarios, activities, or podcasts. 
The design of the book is consistent with its arguments in the chapters; it is an open access and interactive book that excellently fits the needs of the target audience in a digital age verifying McLuhan's (1967) argument "the medium is the message." It includes scenarios, podcasts, videos, takeaways, activities, and comment boxes. It combines theoretical and conceptual knowledge with practical information by presenting scenarios from real life experiences, reflective questions in the activities, podcasts, videos, and the author's observations. I felt a continuous interaction with the author while reading the book. Podcasts involving Bates's opinions on topics, his use of "I" language, and his sharing of his experiences in the texts made me feel his presence during the whole process of reading. There is also an opportunity for readers to write their opinions on questions within the activities in a comment box and discuss the topic. Moreover, there are takeaways that present the key points related to the topic in the beginning and at the end of the chapters. Readers also receive a very comprehensive reference list and a bibliography. The language of the book is notably flowing and easily understood. Novice teachers, instructors, researchers, and non-native speakers of English can easily comprehend the chapters and apply the guidelines suggested when making decisions about their teaching.

In all, Bates's book is a must-read reference book for teachers, instructors, researchers, practitioners, and students in the field of educational technology and open and distance learning.

\section{Reference}

McLuhan, M. (1967). Understanding media: The extensions of man. New York: McGraw-Hill.

\section{Athabasca}

University

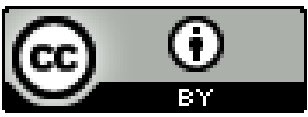

